\title{
EL SENTIMIENTO TRÁGICO DE UNAMUNO Y BAROJA Edgar Vite*
}

RESUMEN: El autor examina las características de la Generación del 98 por medio de una selección de textos de dos de sus representantes más significativos: Miguel de Unamuno y Pío Baroja. A partir de un estudio comparativo, analiza los temas principales de sus novelas y las preocupaciones que los guían, poniendo especial énfasis en sus semejanzas y diferencias. El hilo conductor de este análisis crítico consiste en rastrear la influencia del existencialismo en sus novelas. Éste se refleja en la obra de ambos escritores mediante una estética trágica y sombría, y el monólogo y la introspección como recursos estilísticos; el protagonista se presenta como forjador de su destino, además de mostrarse en una lucha constante con el resto de los personajes. La trama de sus novelas suele guiarse por una serie de implicaciones éticas, además de hacer reflexionar al lector sobre el lugar de la trascendencia y el sentido de la muerte.

PALABRAS ClaVE: Generación del 98, existencialismo, literatura comparada, Unamuno, Baroja.
ABSTRACT: In this article, the characteristics of Generation 1898 are analyzed in selected works of its most significant writers, Miguel de Unamuno and Pio Baroja. A comparative study of their main ideas and concerns in those works with a special emphasis placed on their similarities and differences will be addressed. The common theme for this critical analysis is to demonstrate the importance of existentialism in their novels. Examples of this influence are seen in their use of a dark and tragic esthetic, monologue and introspection as stylistic tools, the protagonist as creator of his own destiny, as well as his continuous struggle with the other characters. The plot in these novels addresses ethical issues as well as allowing the reader to contemplate the role of transcendence and the meaning of death.

KEYWORDS: Generation of 1898, existencialism, comparative literature, Unamuno, Baroja.

RECEPCIÓN:16 de enero de 2008.

ACEPTACIÓN:17 de abril de 2008.

* Departamento Académico de Estudios Generales, ITAM. 


\section{EL SENTIMIENTO TRÁGICO DE UNAMUNO Y BAROJA}

Si del todo morimos todos, ¿para qué todo? ¿Para qué? Es el ¿para qué? de la Esfinge, que nos corroe el meollo del alma, es el padre de la congoja, la que nos da el amor de esperanza.

Miguel de Unamuno, Del sentimiento trágico de la vida

uiero comenzar situando a Pío Baroja y a Miguel de Unamuno como pensadores y novelistas copartícipes de la crisis moral de España en 1898, la cual no sólo generó en ellos una postura intelectual, sino que les dio las armas para reflexionar en torno al sentido de la vida y de su propia existencia. En el fondo, ambos encontraron una configuración trágica de la vida, desde la que propusieron su respuesta personal. ${ }^{1}$

${ }^{1}$ Aunada a la crisis económica y social, es necesario considerar también una crisis ideológica e intelectual, que no era exclusiva de España, sino que fue común al fin de siglo en Europa. Sobre este punto, Pedro Cerezo nos muestra que la crisis del 98 y el movimiento intelectual correspondiente a la misma, no fue un evento local, ni aislado, sino que responde a una sensibilidad y decadencia compartidas. Por esta razón, a Cerezo le parece más adecuada la interpretación de Baroja sobre su
Miguel de Unamuno entabló una constante lucha en contra de una concepción abstracta del mundo y del hombre. Para el filósofo vasco, lo más importante era la propia existencia y no la reflexión sobre ella, aunque, paradójicamente, dedicó

época que la de sus contemporáneos: "A mi juicio, Baroja fue más perspicaz al poner el sello característico de su generación, no tanto en el problema de España como en una situación espiritual afín a toda Europa, que se anunciaba tanto en el modernismo literario como en el tragicismo filosófico. El verdadero epicentro espiritual de la crisis del 98, por seguir utilizando el lenguaje orteguiano, no provenía de la mitología nacional, en contra de lo que creía Ortega, sino que trascendió con mucho la circunstancia española, provocada por el Desastre, para inscribirse en la otra crisis espiritual que se extendió por la Europa finisecular como la gran sombra de la cultura ilustrada." Pedro Cerezo, "La doble crisis, ideológica e intelectual, del 98", en Leopoldo Zea y Ma. Teresa Miaja, comps., 98 : Derrota pírrica, 2000, México, FCE. 
gran parte de su vida y obra a esta actividad.

Unamuno presenta un planteamiento antropológico que deja de lado toda concepción ideal del hombre para ofrecernos una filosofía existencial: ¿quién mejor para reflexionar sobre su propia vida, sino aquél a quien más le concierne? Por esta razón para Unamuno lo más importante es el hombre concreto, el ser humano particular.

Así lo leemos en Niebla cuando hablan Augusto y don Avito:

Sí Augusto, sí -prosiguió don Avito-; la vida es la única maestra de la vida; no hay pedagogía que valga. Sólo se aprende a vivir viviendo, y cada hombre tiene que recomenzar el aprendizaje de la vida de nuevo. ${ }^{2}$

Por su parte, la introspección no es un estado ajeno a Pío Baroja, para quien la reflexión en torno a la propia existencia adquiere un lugar central. En el caso de este otro autor vasco, encontramos en sus novelas una forma de autoconocimiento, que en lugar de brindarnos la tranquilidad de una respuesta, nos lleva a una cierta sensación de vacío e inclusive de desesperación.

De este modo es como Andrés Hurtado, el protagonista de El árbol p. 152 . de la ciencia, comienza a descubrir lo angustiosa que puede resultar la reflexión, sobre todo de la propia existencia:

Fuera de aquellos momentos [...] el estudio, las discusiones, la casa, los amigos, sus correrías [...] mezclado con sus pensamientos, le daba una impresión de dolor, de amargura en el espíritu. La vida en general, y sobre todo la suya, le parecía una cosa fea, turbia, dolorosa e indomable. ${ }^{3}$

Partiendo de la noción de existencia e introspección, Unamuno se enfrenta al racionalismo, pues para él la facultad intelectual no es lo esencial en el hombre. De hecho, le parece que son más indispensables los sentimientos, los impulsos y las pasiones, es decir, todo aquello que nos mueve por dentro, que nos anima o nos deja sin aliento, marcando el sentido de la propia vida, como cuando se sufre la pérdida de un ser querido. Esto es lo que nos refleja don Avito en Niebla, cuando habla de la muerte de su hijo:

Desde que mi pobre Apolodoro, mi víctima $-\mathrm{y}$ al decir esto le lloraba la voz- murió, es decir se mató, no hay ya presente posible, no hay ciencia ni realidad que valgan

${ }^{3}$ Pío Baroja, El árbol de la ciencia, 1985, Madrid, Cátedra, p. 60. 
para mí, no puedo vivir sino recordándole o esperándole. ${ }^{4}$

La dolorosa introspección es compartida por Baroja, para quien la fraternidad y la compasión parecen haberse perdido totalmente. En esta medida no sólo nos muestra un marcado distanciamiento entre los seres humanos, sino el terrible daño que podemos causarnos. Para dicho autor, la sociedad de su época se corrompió por su fuerte egoísmo; la sociedad española perdió de vista la más mínima noción de dignidad humana. Esto se aprecia, contradictoriamente, en personajes cuyo contacto con los otros resulta esencial:

El médico de la sala, amigo de Julio, era un vejete ridículo, con unas largas patillas blancas. El hombre, aunque no sabía gran cosa, quería darse aire de catedrático, lo cual a nadie podía parecer un crimen; lo miserable, lo canallesco era que trataba con una crueldad inútil a aquellas desdichadas acogidas allí y maltratadas de palabra y de obra. ${ }^{5}$

Dicha deshumanización va a dar lugar a una serie de situaciones dramáticas, donde encontramos que el beneficio individual será perseguido a cualquier costo, aun en perjuicio de

${ }^{4}$ Unamuno, Niebla, op. cit., p. 152.

${ }^{5}$ Pío Baroja, El árbol de la ciencia, op. cit., p. 79. alguien más. Pío Baroja nos presenta casos concretos donde se usa al prójimo sin el menor escrúpulo. Así es como Aracil, uno de los compañeros de Hurtado, se aprovecha de la pobreza de una joven, sin importarle el daño que pueda causarle:

- ¿Te vas a casar con ella después? -iQuita de ahí, hombre! No sería mal imbécil.

-Pero has inutilizado a la muchacha.

-¡Yo! ¡Qué estupidez! ${ }^{6}$

Un tema común en ambos autores es el de la naturaleza contradictoria. Según Unamuno los seres humanos nos constituimos por principios opuestos, pues somos un alma encerrada en un cuerpo; no somos seres acabados, y por eso, vivimos en una constante dialéctica; pero lo trágico no es que las necesidades nos aten al cuerpo, ni que las pasiones alteren la dirección de nuestras acciones, sino más bien que nuestra propia naturaleza está fragmentada. Podemos movernos en ambos planos, el más alto y el más bajo; somos seres limitados, que se proyectan al infinito.

La contradicción no termina aquí; Miguel de Unamuno se refiere también a la clara oposición que existe entre razón y sentimientos, entre nuestra experiencia del mundo y nuestras ideas sobre el mismo.

${ }^{6}$ Ibid., p. 92. 
Unamuno se inclina más por los sentimientos y esto se debe a que la razón por sí sola le parece insuficiente. El filósofo español plantea que la razón es lo opuesto a la vida; la razón, en su opinión, da muerte a la vida. En sus palabras:

Por cualquier lado que la cosa se mire, siempre resulta que la razón se pone enfrente de ese nuestro anhelo de inmortalidad personal, y nos le contradice. $\mathrm{Y}$ es que, en rigor, la razón es enemiga de la vida. ${ }^{7}$

La crítica de Pío Baroja a la confianza ciega en la razón no sólo hace referencia a la ciencia, sino también apunta a un estancamiento del conocimiento, porque éste termina reduciéndose a la repetición de ciertos modelos obsoletos. Desde su perspectiva, la ciencia fracasa y por tanto el progreso que le adjudicamos no es más que una ilusión. Un claro ejemplo de esto es el momento en que muere el hermano menor de Hurtado, a pesar de todos sus esfuerzos por salvarlo:

Andrés escribió a su padre y a Margarita. Cuando recibió la carta de su hermana, pudo seguir la marcha de la enfermedad de Luisito. Había tenido una meningitis tuberculosa, con dos o tres días de un período

${ }^{7}$ Unamuno, Del sentimiento trágico de la vida, 1964, Buenos Aires, Losada, p. 85. prodrómico, y luego una fiebre alta que hizo perder al niño el conocimiento; así había estado una semana gritando, delirando, hasta morir en un sueño. ${ }^{8}$

La reflexión sobre la existencia se conecta con el tema de la personalidad. Al respecto, Unamuno sugiere que no sólo se trata de averiguar qué somos, sino quiénes somos. Para él la pregunta correcta no es ¿qué es el hombre?, sino ¿quién soy yo? El primer síntoma de este cuestionamiento es la angustia que sentimos frente al abismo de la propia existencia.

En Pío Baroja el descubrimiento de la personalidad nos pone a prueba, pues dudamos sobre el camino que debemos tomar. Este conflicto se nos presenta de forma palpable en la lucha interna que lleva a cabo Hurtado para establecer su lugar en el mundo. Lo particular de dicho personaje consiste en que se muestra en constante batalla con el mundo, pero sobre todo con los otros. El choque entre su personalidad y la de los demás resulta inconciliable.

Hurtado no se siente identificado con prácticamente nada ni nadie $\mathrm{y}$ esto nos revela el lugar de la soledad en la construcción de nosotros mismos:

${ }^{8}$ Pío Baroja, El árbol de la ciencia, op. cit., p. 153. 
Para llegar al nuevo cuarto de Andrés había que subir unas escaleras, lo que le dejaba completamente independiente [...] Allá se encontraba a su gusto, solo; decía que estudiaba mejor con aquel silencio; pero muchas veces se pasaba el tiempo leyendo novelas o mirando sencillamente por la ventana. ${ }^{9}$

Claro que esta búsqueda por la soledad no sólo se debe a la profunda necesidad de introspección que siente Andrés Hurtado, sino también al hecho de que su relación con la sociedad lo obliga a aislarse. No puede sentirse identificado con nada externo, de hecho lo que está fuera lo suele percibir de forma hostil y desgarradora. Tal escisión hace que se retraiga, que el único lugar donde encuentre refugio sea él y por esta razón se vuelve tan ensimismado.

Sólo respondiendo a la cuestión sobre la identidad podremos establecer una dirección en nuestra vida. Para Miguel de Unamuno la duda es aquello que nos motiva a dar el gran paso, después del cual no hay marcha atrás. ${ }^{10}$ El peso de la existencia puede

${ }^{9}$ Ibid., p. 49.

${ }^{10}$ El filósofo español nos muestra que la duda es el detonante de la reflexión, pero, sobre todo, nos plantea que la duda es condición necesaria del pensamiento. De algún modo, Unamuno sugiere que somos escépticos por naturaleza y esto se debe al hecho mismo de que somos conscientes de nuestra propia existencia. Así, nos presenta una dialéctica que va de la estaticidad de lo conocido al dinamismo producido por la inquietud de la ser terrible, lo que nos recuerda la constante agonía en la que se encuentra Augusto; agonía causada, en último término, por el escepticismo ${ }^{11}$ que profesa hacia su persona:

- Yo por lo menos sé de mí decirte que una de las cosas que me da más pavor es quedarme mirándome al espejo, a solas, cuando nadie me ve. Acabo por dudar de mi propia existencia e imaginarme, viéndome como otro, que soy un sueño, un ente de ficción...

- Pues no te mires así...

- No puedo remediarlo. Tengo la manía de la instrospección. ${ }^{12}$

De aquí que nos resulte tan terrible dejar de ser, dejar de existir. Para Unamuno la personalidad es lo esencial de cada hombre; por eso nos resulta inconcebible nuestra propia muerte. Al filósofo español le parece absurda la negación de uno mismo

duda: "Y pensar es dudar y nada más que dudar. Se cree, se sabe, se imagina sin dudar; ni la fe, ni el conocimiento, ni la imaginación suponen duda y hasta la duda las destruye, pero no se piensa sin dudar. Y es la duda lo que de la fe y del conocimiento, que son algo estático, quieto muerto, hace pensamiento, que es dinámico, inquieto, vivo", Unamuno, Niebla, op. cit., p. 223.

${ }^{11}$ En el caso de Baroja no podríamos hablar tanto de un escepticismo, sino más bien de un desencanto de la humanidad. Hurtado no duda de su propia existencia, sino que más bien pierde la fe en los demás. No es el abismo interno lo que le resulta terrible, sino el abismo externo. Será una clara diferencia entre el planteamiento de Baroja y el de Unamuno.

${ }^{12}$ Unamuno, Niebla, op. cit., p. 210. 
e inclusive el hecho de que alguien desee ser otro:

Eso es lo que yo no acabo nunca de comprender, que uno quiera ser otro cualquiera. Querer ser otro es querer dejar de ser uno el que es. Me explico que uno desee tener lo que otro tiene, sus riquezas o sus conocimientos; pero ser otro, es cosa que no me la explico. ${ }^{13}$

Dicho escepticismo no es un planteamiento alejado de nosotros mismos, no es un conflicto fingido, sino el resultado de la propia existencia. El filósofo español no considera que nuestra capacidad racional nos lleve a un escepticismo intelectual, sino que dicho escepticismo se deriva del choque entre la estaticidad del pensamiento y el dinamismo inherente a la vida. Así lo expresa Augusto:

No es, en rigor, que la razón nos lleve al escepticismo absoluto, ¡no! La razón no me lleva ni puede llevarme a dudar de que exista; adonde la razón me lleva es al escepticismo vital; mejor aún a la negación vital; no ya a dudar, sino a negar que mi conciencia sobreviva a mi muerte. El escepticismo vital viene del choque entre la razón y el deseo. Y de este choque, de este abrazo entre la desesperación y el escepticismo,

${ }^{13}$ Unamuno, Del sentimiento trágico de la vida, op. cit., p. 14. nace la santa, la dulce, la salvadora incertidumbre, nuestro supremo consuelo. ${ }^{14}$

De aquí se desprende lo que Unamuno ha denominado como el sentimiento trágico de la vida: se trata de esta resistencia, de esta escisión entre nuestro deseo de supervivencia y los límites de nuestra propia naturaleza. Lo más difícil es resignarnos. ¿Cómo aceptar el hecho de que algún día dejaremos de vivir, si lo propio es la existencia? Este es el camino por el cual Unamuno llega al problema de la inmortalidad del alma y así se cuestiona sobre la vida futura.

Por el hecho de ser mortales nos aferramos a la vida, pero sobre todo desarrollamos un enorme anhelo por mantenernos en ella, de ahí nuestra búsqueda de eternidad:

¡Eternidad! ¡Eternidad! Éste es el anhelo; la sed de eternidad es lo que se llama amor entre los hombres, y quien a otro ama es que quiere eternizarse en él. Lo que no es eterno tampoco es real. ${ }^{15}$

Tal deseo de permanencia no debe entenderse simplemente como continuidad física y temporal, sino como continuidad espiritual. De hecho éste es uno de los puntos clave del plan-

\footnotetext{
${ }^{14}$ Ibid., p. 109

${ }^{15}$ Ibid., p. 40.
} 
teamiento de Unamuno, pues para él lo que justifica la vida es la muerte. Gracias a que somos conscientes de que vamos a morir, la vida adquiere un nuevo sentido; podemos decir, incluso, que es entonces cuando todo adquiere sentido.

Al respecto, encontramos una clara diferencia entre el planteamiento de Unamuno y el de Baroja. Para este último no existe nada más allá de la vida terrena. Baroja nos habla continuamente de este problema y no entiende a la muerte como aquello que da sentido a la vida, sino como una parte más de nuestra condición existencial.

Para Pío Baroja la muerte no es más que un obstáculo para los seres vivos; por eso cree que podemos desdeñarla. En las novelas de Baroja encontramos continuas referencias escatológicas en las que se muestra el desdén de ciertos personajes hacia la muerte:

Se contaban muchas historias como ésta, fueran verdad o no, con verdadera fruición. Existía entre los estudiantes de Medicina una tendencia al espíritu de clase, consistente en un común desdén por la muerte; en cierto entusiasmo por la brutalidad quirúrgica y en un gran desprecio por la sensibilidad. ${ }^{16}$ cit., p. 54.
Baroja realiza una conexión entre el significado de la muerte y el egoísmo individual. De aquí se desprende lo que denomina como "la crueldad universal" y consiste en que los individuos solamente ven por sí mismos, sin importarles perjudicar a los otros. La muerte se justifica como un medio para continuar con la existencia, como parte de un ciclo que no se dirige hacia ninguna parte. En consecuencia, la vida en general, y la existencia humana en particular, se vuelve una lucha feroz por la supervivencia; por lo que, en tal estado de cosas, el más fuerte y el más capaz será el que permanezca:

Todo lo que vive tiene un proceso para apoderarse primero del espacio, ocupar un lugar, luego para crecer y multiplicarse; este proceso de la energía de un vivo contra los obstáculos del medio, es lo que llamamos lucha. Respecto de la justicia, yo creo que lo justo en el fondo es lo que nos conviene. Supón en el ejemplo de antes que la hiena en vez de ser muerta por el hombre mata al hombre, que el árbol cae sobre él y le aplasta, que la araña le hace una picadura venenosa, pues nada de eso nos parece justo, porque no nos conviene. ${ }^{17}$

Baroja no sugiere en ningún momento que exista algo más allá y

${ }^{17}$ Ibid., p. 126. 
por tanto elimina cualquier noción de trascendencia. Por otro lado, establece que la vida tiene sentido en sí misma y que no podemos imponerle una finalidad externa. De aquí su fuerte crítica a cualquier tipo de universalización, de la cual se sigue su conclusión de que la idea de justicia no es más que una ilusión:

La naturaleza es lo que tiene, cuando trata de reventar a uno, lo revienta a conciencia. La justicia es una ilusión humana; en el fondo todo es destruir, todo es crear. Cazar, guerrear, digerir, respirar son formas de creación y destrucción al mismo tiempo. ${ }^{18}$

De esta forma nos enfrentamos al tema del suicidio, presentado como una alternativa a este ciclo sin fin, a este destino trágico del hombre. Para Baroja, el suicidio nos pone frente al poder de la libertad, pues a pesar de lo consternante que resulte tomar esa decisión, se nos revela que la continuidad de la existencia está en nuestras manos:

Andrés se había envenenado. Sin duda, la rapidez de la intoxicación no produjo convulsiones ni vómitos. La muerte se había sobrevenido por parálisis inmediata del corazón.

${ }^{18}$ Ibid., p. 129.
-Ha muerto sin dolor -murmuró Iturrioz-- Este muchacho no tenía fuerza para vivir. Era un epicúreo, un aristócrata, aunque él no lo creía.

-Pero había en él algo de precursor-murmuró el otro médico. ${ }^{19}$

Es necesario recalcar que ambos escritores presentan un claro existencialismo, mediante el cual buscan responder a la crisis de su tiempo, pero más allá de limitarse a establecer un planteamiento abstracto, tratan de hallar una salida personal. Los dos desean resolver el problema de la existencia individual, aunque nos llevarán a conclusiones distintas.

Por su parte, Miguel de Unamuno, nos presenta un planteamiento ético, donde la creencia en una vida futura implica una relación de responsabilidad respecto de nuestras acciones. Así, la moral nos revela su verdadero fundamento, es decir, la inmortalidad del alma. No todas las acciones son equiparables; no todo comportamiento está justificado. Por esta razón Unamuno nos muestra una postura ética que incluye la esperanza en una vida futura:

Mi conducta ha de ser la mejor prueba, la prueba moral de mi anhelo supremo; y si no acabo de convencerme, dentro de la última e irremediable incertidumbre, de

${ }^{19}$ Ibid., p. 292. 
la verdad de lo que espero, es que mi conducta no es bastante pura. No se basa, pues, la virtud en el dogma, sino éste en aquélla, y es el mártir el que hace la fe más que la fe el mártir. No hay seguridad y descanso - los que se pueden lograr en esta vida, esencialmente insegura y fatigosa- sino en una conducta apasionadamente buena. ${ }^{20}$

De aquí que el filósofo español no sólo realice un planteamiento antropológico; sino que, una vez establecido qué es el hombre, se cuestiona sobre el modo en que hemos de conducirnos y sobre la dirección que han de tomar nuestras acciones. ${ }^{21}$ Unamuno pretende encontrar un equilibrio entre las diversas facultades, los deseos y los principios que nos constituyen. En esta medida propone una vía intermedia entre el racionalismo y el fideísmo, tratando de conciliar ambas posturas. En esto consiste, precisamente, su propuesta dialéctica. Gracias a ella no se logra la armonía, sino la conciencia de que nuestra naturaleza es inestable, y de

\footnotetext{
${ }^{20}$ Unamuno, Del sentimiento trágico de la vida, op. cit., p. 227.

${ }^{21}$ Por ello, el planteamiento de Unamuno es profundamente ético, pero sobre todo muy personal. La crisis interna se refleja por medio de la crisis externa y viceversa. Por esta razón el filósofo español no puede alejarse de la realidad social que lo rodea, al mismo tiempo que busca encontrar un camino propio. El existencialismo ético presentado por Unamuno no es un existencialismo aislado, sino que implica una conexión con los demás.
}

que en dicha inestabilidad se funda lo esencial de la vida humana.

Me parece que en el fondo este escritor vasco deja lugar para la esperanza y, por tanto, para una salida positiva. Sin embargo, su respuesta no es terminal, y esto se debe al hecho mismo de que lo característico de la dialéctica no es la estaticidad. No se trata de alcanzar un estado total de equilibrio entre nuestros principios contrarios sino, más bien, de no renunciar a ninguno de ellos.

En el caso de Pío Baroja, éste se acerca más al nihilismo, al plantear un existencialismo radicalizado que reduce la vida humana a su estado más primitivo. Lo llamativo de su postura radica en que da un cierto lugar a la esperanza, encarnada en la figura de Andrés Hurtado, quien a pesar de ser consciente del destino trágico del hombre, sigue luchando en contra de la falta de valores y el egoísmo.

En este mismo sentido se nos presentan algunos personajes de $E l$ árbol de la ciencia, como el caso de Lulú, la única por quien Andrés experimenta cierta simpatía y afinidad en el modo como comprende la sinceridad, la honestidad y la lealtad. Así la describe el narrador:

En el fondo de su falta de ilusión y de moral, al menos de moral corriente, tenía esta muchacha una idea muy humana y muy noble de 
las cosas. A ella no le parecían mal el adulterio, ni los vicios, ni las mayores enormidades; lo que le molestaba era el doblez, la hipocresía, la mala fe. Sentía un gran deseo de lealtad. ${ }^{22}$

Por esta razón queda claro que para Baroja los individuos pueden experimentar cierta intuición respecto a lo bueno y lo malo, independientemente de lo absurdo, que le resulta la existencia de una serie de ideas reguladoras y de parámetros de conducta. Por supuesto, al final Andrés Hurtado no logrará cambiar nada, pero luchará en todo momento hasta su muerte.

Así, Baroja nos muestra lo importante que es la individualidad, independientemente de que sea posible o no lograr una identificación con los demás. Para este escritor español, el conflicto también permanece abierto; y es justo en esta escisión donde radica lo trágico de la vida: en la abismal distancia entre unos y otros, cuya consecuencia más terrible consiste en la imposibilidad de conciliar los ideales personales con la condición humana.

${ }^{22}$ Pío Baroja, El árbol de la ciencia, op. cit., p. 110. 
CITAM Derechos Reservados.

La reproducción total o parcial de este artículo se podrá hacer si el ITAM otorga la autorización previamente por escrito. 